\title{
AVALIAR A ILUMINAÇÃO ARTIFICIAL NOS CENTROS CIRÚRGICOS EM CUIABÁ: ESTUDO DE CASO
}

\author{
Tula Kirst Romani \\ Mestranda do Programa de Pós-Graduação de Engenharia de Edificações e Ambiental, Linha de Pesquisa: Conforto \\ Ambiental e Eficiência Energética, E-mail: tulakirst@gmail.com \\ Marta Cristina de Jesus Albuquerque Nogueira \\ Professora do Departamento de Arquitetura e Urbanismo/FAET/UFMT, Professora do Programa de Pós- \\ Graduação de Engenharia de Edificações e Ambiental, Linha de Pesquisa: Conforto Ambiental e Eficiência Energética, \\ E-mail: mcjanp@gmail.com
}

http://dx.doi.org/10.5902/223611707708

\section{RESUMO:}

Para garantir a segurança em cirurgias, além de todos os elementos técnicos do procedimento em si, é necessário que as condições do local onde ele acontece sejam as melhores possíveis no sentido de diminuir as variáveis que podem alterar o resultado dos procedimentos, aumentar o nível de sucesso e preservar a saúde dos profissionais que atuam dentro do centro cirúrgico. Este artigo tem como objetivo geral apontar a importância da iluminação adequada a este setor do hospital e às tarefas nele desenvolvidas, como objetivos específicos foram fazer um perfil deste hospitais para dois estabelecimentos assistenciais de saúde em dois momentos distintos do ano em Cuiabá, verificar seu respeito às normas que ditam os valores mínimos para a iluminação nos ambientes do centro cirúrgico e ainda verificar se há alteração no perfil de iluminação nos ambientes entre os períodos mais secos e úmidos do ano. Os dados foram obtidos através da observação das condições físicas do ambiente e dos equipamentos à disposição destes profissionais no sentido de iluminar o seu ambiente de trabalho, e de baterias de medições dos níveis de iluminamento de salas do centro cirúrgico. Os critérios de análise dos dados obtidos foram a NBR 5413 (1992) que determina os níveis mínimos de iluminamento para os ambientes, e as recomendações para a iluminação em instalações de assistência à saúde da IESNA (Sociedade Americana de Engenharia de lluminação). Os centros cirúrgicos visitados precisam de adequações, pois não atenderam completamente a nenhum dos critérios utilizados na pesquisa. Os níveis de iluminamento se encontram abaixo dos valores mínimos estipulados pela NBR 5413 (1992) em todos os períodos em que foram realizadas as medições, e os equipamentos de iluminação não estão de acordo com as recomendações da IESNA.

Palavras-chave: Iluminação, centro cirúrgico, conforto lumínico.

\section{ABSTRACT:}

To ensure safety in surgery, in addition to all the technical elements of the procedure itself, it is necessary that the conditions of the place where it happens to be the best possible in order to reduce the variables that can alter the outcome of the procedures, increase the level of success and preserve the health of professionals working within the surgical center. This article aims to point out the general importance of proper lighting in this sector of the hospital and the tasks it developed specific objectives were to make a profile of this hospital for two health-care facilities at two different times of the year in Cuiabá, check your respect rules that dictate the 
minimum values for ambient lighting in the operating room and even check for change in the profile of lighting environments between dry and wet periods of the year. Data were collected through observation of the physical environment and equipment available to these professionals to brighten your desktop and battery of measurements of luminance levels of the operating rooms. The criteria for data analysis were the NBR 5413 (1992) which determines the minimum luminance for environments, and recommendations for lighting installations in the healthcare of IESNA (American Society for Engineering Lighting). The popular surgical centers need adjustments because not fully met any of the criteria used in the survey. The luminance levels are below the minimum values set by NBR 5413 (1992) in all periods in which measurements were taken, and the lighting equipment do not conform with the recommendations of IESNA.

Keywords: Lighting, surgical center, luminic comfort.

\section{INTRODUÇÃO}

Muitas pessoas veem o Centro Cirúrgico com os olhos de quem, vez ou outra, foi, ou teve algum parente ou conhecido, submetido a um procedimento terapêutico invasivo.

Os médicos e os enfermeiros dividem com profissionais de emergência, policiais, investidores da bolsa, controladores de tráfego aéreo e professores, o topo da lista das profissões mais estressoras. No caso da equipe do Centro Cirúrgico, a responsabilidade de lidar diretamente com a vida das pessoas e a expectativa delas quanto aos resultados dos procedimentos realizados é uma das principais razões da carga extra de stress a que estes profissionais estão sujeitos.

Os procedimentos realizados dentro do Centro Cirúrgico podem ser simples e rápidos ou extremamente complexos e demorados, mas um elemento é comum a todos eles, o risco, seja pela gravidade dos pacientes ou pela complexidade dos atos anestésico e cirúrgico.

Todos estes fatores dificultam a ação dos cirurgiões e podem trazer como consequência uma queda no rendimento do trabalho do médico e, em casos mais extremos, negligências operacionais. Estas podem gerar consequências graves para o profissional, para a instituição e principalmente para o paciente.

Visualizar tarefas delicadas com iluminação inadequada exige esforço extra que absorve parte da energia e atenção que deveriam estar dirigidas à tarefa. Isso pode acarretar um aumento do desgaste físico e da tensão relacionada à atividade dentro do Centro Cirúrgico.

Cuiabá, capital do estado de Mato Grosso, é considerada um centro de referência médica na região e atende, além da população da cidade, diversos municípios do estado. Possui vários hospitais e centros cirúrgicos que recebem pacientes do sistema único de saúde do governo, clientes de planos de saúde e pacientes particulares. No entanto, poucos estudos têm sido feitos quanto à qualidade ambiental dos centros cirúrgicos em nossa capital.

A coleta de dados a respeito da qualidade física do ambiente de trabalho da equipe de cirurgia em Cuiabá é de extrema importância para que se verifique a obediência às normas existentes acerca do tema e se possa garantir um ambiente favorável a pratica a que se destina os centros cirúrgicos.

O centro cirúrgico, objeto de estudo deste trabalho, é um importante setor dentro da estrutura de assistência à saúde por se tratar do ambiente onde são realizados os procedimentos cirúrgicos com finalidade de cura terapêutica ou estética, que são, em sua maioria, parte fundamental de tratamentos que buscam o reestabelecimento da saúde dos pacientes. 
A intenção deste trabalho é demonstrar as importâncias de adequadas condições lumínicas baseado na recomendação da norma apresentado pela Associação Brasileira de Normas Técnicas (ABNT), para que possam haver boa atuação dos profissionais que trabalham nos centros cirúrgicos e apresentarem condições reais a que estes trabalhadores estão sujeitos nestes ambientes na capital do estado do Mato Grosso.

\section{MATERIAIS E MÉTODOS}

\subsection{MATERIAIS}

Os materiais utilizados para a coleta dos dados dentro dos ambientes estudados foram:

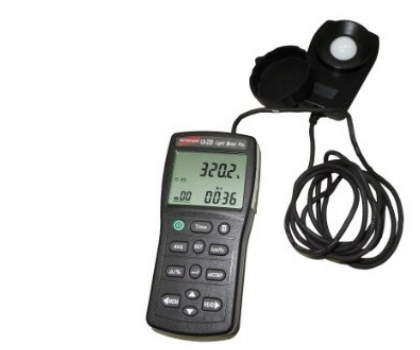

Figura 01 - Luxímetro Instrutherm, modelo LD-220

FONTE: Arquivo próprio

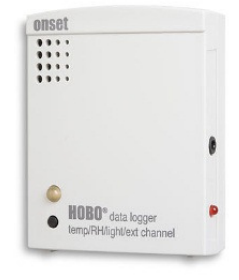

Figura 02 - Data logger Onset, modelo HOBO U12-012

FONTE: Arquivo próprio

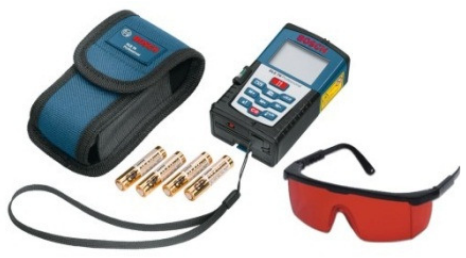

Figura 03 - Trena a laser Bosch, modelo DLE 70

FONTE: Arquivo próprio

\subsection{MÉTODO}

Os centros cirúrgicos são ambientes altamente restritos pela própria natureza dos procedimentos dentro dele realizados e a necessidade de limpeza absoluta dentro de suas dependências, logo, a definição dos locais de pesquisa esteve, desde o início da montagem do trabalho dependente da obtenção de permissão de acesso aos centros cirúrgicos existentes na cidade. Este foi o principal critério para a definição dos hospitais a terem suas instalações analisadas, muito mais do que os de localização, das características da população atendida ou das especialidades de cada uma das instituições.

Cuiabá conta com vinte e três hospitais, sendo treze hospitais gerais e dez hospitais especializados. Entre eles encontram-se dois que atendem alunos de cursos de medicina e residência médica (CNESNet, Disponível em http://cnes.datasus.gov.br/. Acesso em 02/01/2013). Dois destes estabelecimentos permitiram a instalação de equipamentos e a coleta de dados em suas dependências, além de colocar as enfermeiras responsáveis pelo local à disposição para acompanhamento e esclarecimentos quanto ao uso do espaço, características do trabalho e a dinâmica dos profissionais dentro do Centro Cirúrgico.

Como no início do processo de levantamento de dados os instrumentos foram divididos em dois grupos de quatro, definindo a quantidade de ambientes a serem pesquisados em cada um dos Estabelecimentos Assistenciais de Saúde participantes.

Dentro de cada Centro Cirúrgico foram definidos quatro ambientes a serem analisados. 0 critério de escolha destes ambientes está ligado diretamente à relevância de cada um destes ambientes nos procedimentos realizados neste setor do hospital. Ficando assim definidas: salas de cirurgia, que contam com dois exemplares para cada hospital, farmácia e a sala de Recuperação Pós-Anestésica (R.P.A.). Uma delas deveria sempre ser uma sala em que acontecem, entre outras 
cirurgias, partos cirúrgicos, assim estaríamos cobrindo com este estudo também as salas de cirurgias obstétricas. A outra é sempre uma sala considerada uma sala grande, onde ocorrem cirurgias mais complexas, como cirurgias cardíacas.

Com os dados em mãos foi feito o comparativo dos valores obtidos com os valores estabelecidos pela NBR 5413 (1992) para cada um dos ambientes. Também foi realizada uma análise das condições do sistema de iluminação em cada um dos locais estudados, os tipos de lâmpadas e luminárias, e as influências exercidas pelas características físicas do ambiente no resultado da iluminação promovida pelo sistema instalado e na atividade dos profissionais dentro dos ambientes.

\section{APRESENTAÇÃO E ANÁLISE DOS RESULTADOS}

\subsection{Coleta de Dados}

A primeira coleta de dados foi realizada no inverno, e as datas exatas para a instalação dos equipamentos foi ditada pela equipe dos hospitais de acordo com a disponibilidade dos profissionais que nos acompanhariam durante o processo de levantamento, e de acordo com a disponibilidade das próprias salas.

Esta primeira bateria foi realizada então nos dias 7, 8 e 9 de agosto de 2012 nos hospitais A e B. Após a realização da medição dos ambientes e a instalação dos equipamentos foi feito um memorial descritivo dos equipamentos componentes dos sistemas de iluminação existentes em cada ambiente. Foi também realizado um levantamento das caraterísticas físicas do local, como material das paredes, cores, tipo de piso, dimensões, existência ou não de aberturas para o exterior e posicionamento do ambiente dentro da estrutura do Centro Cirúrgico.

A coleta manual de dados referente aos níveis de iluminamento dentro dos ambientes foi inicialmente realizada de acordo com a NBR-5382 (1985), mas poucas salas apresentavam as características necessárias para a aplicação desta norma na verificação da iluminância. 0 levantamento foi então realizado a partir do desenho de uma malha de $0,50 \mathrm{~m} \times 0,50 \mathrm{~m}$ no ambiente, que serviu de guia para a tomada dos níveis de iluminamento com o uso do luxímetro. A cada ponto de interseção das linhas da malha foi tomada uma medida após a estabilização das fotocélulas do aparelho conforme especificação da NBR-5382 (1985).

A medição com o uso da malha permitiu que se verificassem as variações dos níveis de iluminamento de cada setor dentro das salas e as influências que os equipamentos médicos e a estrutura física da sala exercem sobre o mesmo.

Também foi realizada a medição dos níveis de iluminamento nos mesmos pontos com o foco cirúrgico acesso e apontado para o centro da mesa de cirurgia para verificar a influência desta luz em seu entorno imediato.

\subsection{HOSPITAIS ANALISADOS}

\subsubsection{Hospital A}

Este hospital iniciou suas atividades em Cuiabá em 1984 (Disponível em: http://www. hospitaljardimcuiaba.com.br/institucional.html. Acesso em 15/09/2012). Trata-se de um hospital Geral, de esfera administrativa privada, pessoa jurídica com fins lucrativos, que atende pacientes particulares e planos de saúde privados. Não há atividade de ensino dentro de suas instalações. Possui oitenta e um leitos, sendo cinquenta e sete cirúrgicos. Seu Centro Cirúrgico é dotado de nove salas de cirurgia, além de todos os ambientes de apoio descritos na RDC 50. 


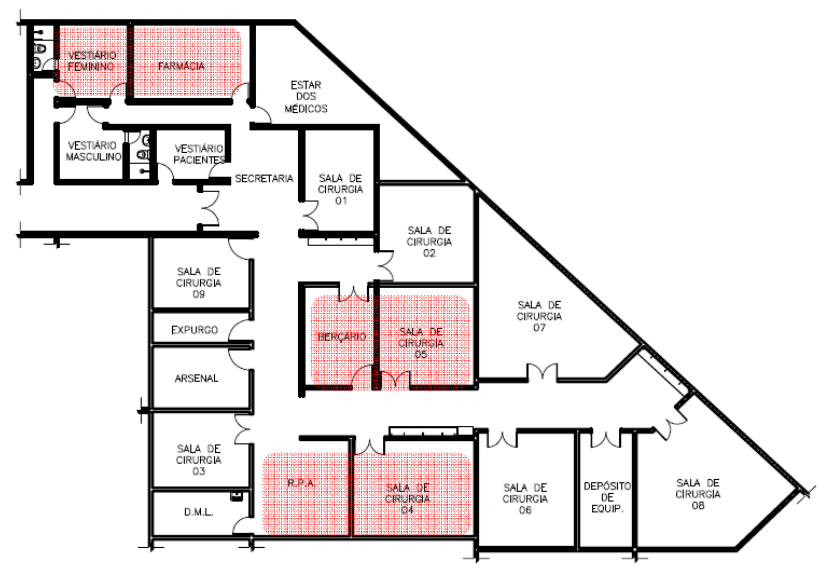

FIGURA 04: Planta baixa do Centro Cirúrgico do Hospital A FONTE: arquivo próprio

Dentro deste Centro Cirúrgico foram analisados os ambientes indicados na planta baixa da Figura 04 com o preenchimento vermelho.

\section{a) Farmácia}

Como os níveis mínimos para a iluminação geral para este ambiente de acordo com a NBR 5413 (1992) é de 150 lux, podemos dizer que este sistema de iluminação está antendendo às necessidades do local na maioria dos pontos medidos no período de agosto de 2012. Esta informação é confirmada pelo resultado da média da iluminação do local aferida pelo HOBO na primeira bateria de três dias consecutivos de medições dentro do ambiente, que foi de 225 lux.

No entanto os níveis de iluminamento caem nas posições próximas aos móveis, pois não há como contar com o relexo da iluminação nas paredes nestes locais fazendo com que os valores mínimos exigidos por norma para este ambiente não sejam atingidos em todos os pontos da malha.

A medição realizada em dezembro apontou um decréscimo grande nos níveis de iluminamento em praticamente todos os pontos da malha dentro da farmácia.

A pouca quantidade de luminárias dentro do ambiente, assim como a sua distribuição, fazem com que seja praticamente impossível evitar o sombreamento causado pelo corpo do profissional ao se aproximar dos armários e prateleiras, obrigando-os a virar o corpo para poder visualizar o nome impresso nos materiais.

Esta mesma NBR aponta como 500 lux o nível mínimo de iluminamento para a mesa de trabalho dentro da farmácia. Não existe um único local com esta quantidade de lux dentro deste ambiente, fazendo com que seja fundamental o incremento do sistema para o atendimento à norma.

\section{b) Recuperação Pós-Anestésica (R.P.A.)}

Não há, na NBR 5413 (1992), uma indicação específica para os níveis de iluminamento deste ambiente, no entanto, a importância do monitoramento das condições do paciente durante este momento, faz com que as exigências para os níveis de iluminamento sejam os mesmos da iluminação geral da sala de cirurgia, mas com o peso de velocidade e precisão da tarefa crítico descartado, o que leva o valor para os 500 lux. 
Este valor não foi encontrado em nenhum dos pontos de medição da malha dentro do R.P.A. A média aritmética da medição manual de agosto e dezembro ficou muito aquém dos níveis mínimos exigidos pela NBR 5413 (1992), bem como a média dos três dias da primeira bateria de medições.

Foi verificada também uma queda nos níveis de iluminamento na segunda medição manual, realizada em dezembro 2012 com relação à medição realizada em agosto. Isso pode ter sido ocasionado por uma série de fatores, como a possibilidade de as lâmpadas estarem no fim de sua vida útil, causando a queda na intensidade do fluxo luminoso, ou a simples falta de limpeza do sistema.

Uma questão bastante importante neste ambiente é o I.R.C., para que seja possível verificar as condições das incisões e da cor da pele dos pacientes. Neste quesito as lâmpadas instaladas oferecem a reprodução de cores necessárias, pois são da linha "luz do dia" que oferecem um I.R.C. bastante elevado.

Apesar de poucos móveis no ambiente, as prateleiras colocadas exatamente acima da posição da cabeça dos pacientes em observação geram um sombreamento que leva os níveis de iluminamento ainda mais para baixo, dificultando a visualização da face dos pacientes.

Existe também a recomendação de que as luminárias possuam proteção de vidro ou acrílico para evitar que algum acidente com as lâmpadas possam causar danos aos pacientes acomodados abaixo, e nenhuma das luminárias deste ambiente apresentou tal proteção.

\section{c) Sala de cirurgia 4 e 5}

Os níveis de iluminamento dos sistemas instalados nestas salas não atendem a NBR 5413 (1992). O sistema de iluminação geral está muito aquém dos 750 lux especificados nesta norma pelas características físicas do ambiente, das tarefas nele desenvolvidas e da população que nele trabalha. O foco cirúrgico também não atende esta nerma. Na melhor das hipóteses, atinge uma quarta porção dos níveis exigidos para a tarefa a que se destina esta iluminação de acordo com a Tabela de iluminânicas por classe de tarefas visuais.

As luminárias do sistema de iluminação geral desta sala de cirurgia também não possuem qualquer tipo de proteção. As lâmpadas estão expostas e, desta forma, sujeitam os pacientes e a equpe dentro do centro cirúrgio ao risco de acidentes caso alguma destas lâmpadas quebre.

A heterogeidade na temperatura de cor das lâmpadas indica que não houve a preocupação com a manutenção desta característica para o sistema.

\subsubsection{Hospital B}

Em funcionamento na Capital desde 1981 (http://www.hmsm.com.br), trata-se de um hospital Geral de esfera administrativa privada, pessoa jurídica com fins lucrativos, que atende a pacientes particulares e planos de saúde privados. Não há atividade de ensino dentro de suas instalações. Possui 115 leitos, sendo 39 destes leitos cirúrgicos. Seu Centro Cirúrgico é dotado de sete salas de cirurgia, além de todos os ambientes de apoio descritos na RDC 50.

Os ambientes analisados são aqueles indicados na planta baixa da Figura 05 com preenchimento vermelho. 


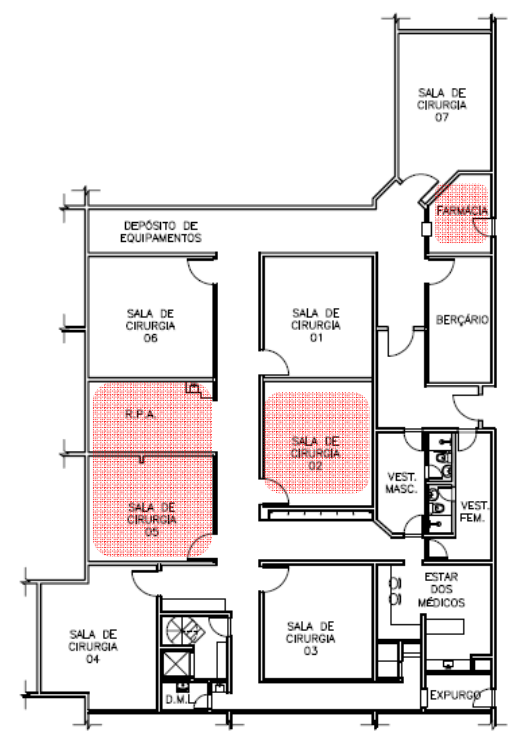

FIGURA 05 - Planta baixa do Centro Cirúrgico - Hospital B

FONTE: arquivo próprio

\section{a) Farmácia}

A farmácia, assim como todos os ambientes do Centro Cirúrgico deste hospital, é um ambiente interno, ou seja, não possui aberturas para o exterior. O seu acesso principal se dá para um corredor, o que facilita o acesso de funcionários para reposição de material. A comunicação deste ambiente com o Centro Cirúrgico acontece através de uma janela, através da qual é passado os containers com os materiais a serem utilizados nos procedimentos.

Dentro desta farmácia existe somente um sistema de iluminação, formado por duas luminárias para quatro lâmpadas fluorescentes tubulares do tipo T5 de quatorze Watts cada, Figura 06. As luminárias, apesar de não possuírem sistema de proteção, contam com refletores e aletas que redirecionam o fluxo luminoso para baixo.

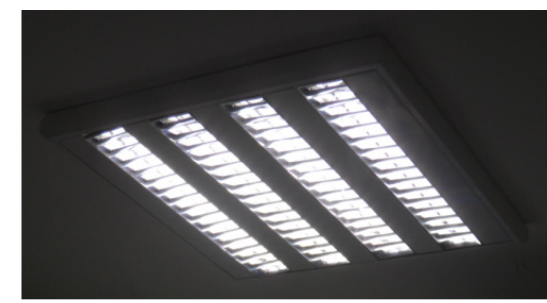

FIGURA 06 - Luminária da farmácia - Hospital B FONTE: arquivo próprio

Como o armário era relativamente alto, com um metro e meio de altura, o aparelho ficou muito próximo da luminária, então a média das medidas tomadas pelo HOBO nesta farmácia nos três dias da primeira bateria de medições foi de 765 lux.

\section{b) Recuperação Pós-Anestésica (R.P.A.)}

Com pouco mais de $16 \mathrm{~m}^{2}$, a sala de Recuperação Pós-Anestésica (R.P.A.) possui a mesma altura de pé direito da farmácia, 2,56m. O teto é revestido com uma tinta fosca branca. As paredes são brancas acetinadas, também brancas, mas com uma faixa azul feita de paviflex aplicado sobre 
a tinta para proteção quanto á pancadas causadas pelas macas. Um paviflex desta mesma cor, mas um pouco mais claro, reveste o piso de todo o Centro Cirúrgico.

Em vários pontos das paredes existem instalações, dutos e prateleiras para apoio de equipamentos de monitoramento e suporte aos pacientes em observação. Estas instalações bloqueiam parte do reflexo das paredes, fazendo com que se formem pequenos sombreamentos.

Na primeira medição deste ambiente, realizado em agosto, as duas luminárias estavam com uma das lâmpadas emitindo somente parte do fluxo luminoso que era esperado da mesma, o que fez com que os valores obtidos ficassem muito abaixo dos valores encontrados na segunda medição. Esta foi realizada em dezembro, e o sistema já havia passado pela manutenção, que consisitiu na troca do conjunto todo de lâmpadas.

A média aritmética da medição realizada no dia 06/08/2012, com todo o sistema de iluminação acionado, mas ainda com as lâmpadas defeituosas, foi de 202 lux. A média aritmética da medição realizada no dia 18/12/2012, após a manutenção das luminárias e com todo o sistema de iluminação acionado foi de 426 lux.

\section{c) Sala de cirurgia 2}

Considerada uma sala de cirurgia grande, a sala de cirurgia 2 do hospital B possui características muito parecidas com os demais ambientes do Centro Cirúrgico. Seu pé direito tem os mesmos $2,56 \mathrm{~m}$ de altura, seu teto é revestido de tinta branca fosca, suas paredes são da mesma cor. Seu piso, no entanto, é diferente, seu revestimento é feito de granilite cinza, Figura 07.

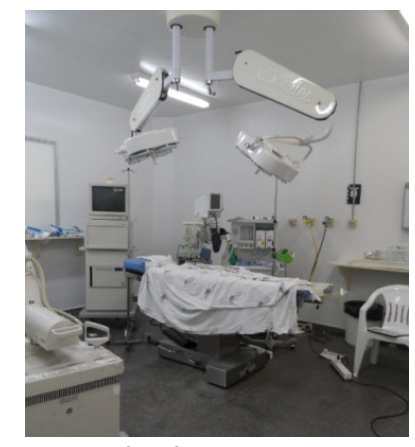

FIGURA 07 - Sala de cirurgia 2 - Hospital B

FONTE: arquivo próprio

Esta sala conta com dois sistemas fixos de iluminação, o geral e o de tarefa. O geral é composto por quatro luminárias sem proteção, refletores ou aletas, que acomodam duas lâmpadas fluorescentes tubulares do tipo T8 de 40W cada, como pode ser visto na Figura 08.

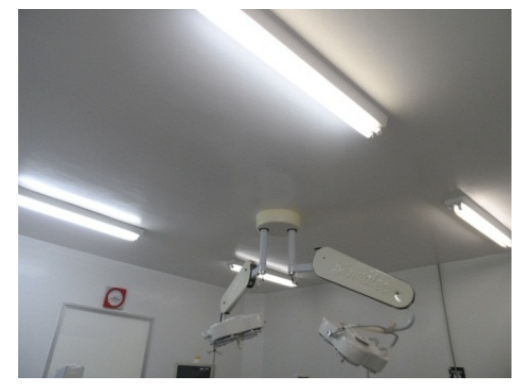

FIGURA 08 - Sistemas de iluminação da sala de cirurgia 2 - Hospital B 
FONTE: arquivo próprio

O sistema de iluminação de tarefa é composto por dois braços articuláveis, com quatro lâmpadas de multivapores metálicos protegidas por uma cúpula de vidro em cada um destes braços. Por serem articulados, este sistema pode ser posicionado de acordo com a necessidade da equipe durante o procedimento. Quando acesso em sua maior potência este foco pode atingir os 13.770lux.

A média aritmética da medição realizada no dia 06/08/2012, com todo o sistema de iluminação acionado foi de 368 lux. A média aritmética da medição realizada no dia 18/12/2012, noite anterior ao início da segunda bateria de medição com o HOBO, após a manutenção das luminárias e com todo o sistema de iluminação acionado foi de 323 lux.

Nesta sala também houve uma limitação com relação ao local para a instalação do HOBO. Assim como nas demais salas de cirurgia não há um local para a instalação do equipamento próximo ao campo cirúrgico, então o negatoscópio virou apoio para este equipamento. A média das medidas tomadas nesta sala de cirurgia nos três dia da primeira bateria de medição foi de 269lux.

\section{d) Sala de cirurgia 5}

A sala de cirurgia 5 é uma sala grande, tem cerca de $25 \mathrm{~m}^{2}$. O seu teto tem duas alturas de pé direito como pode ser observado na figura 105, e é revestido com tinta branca fosca, Figura 09.

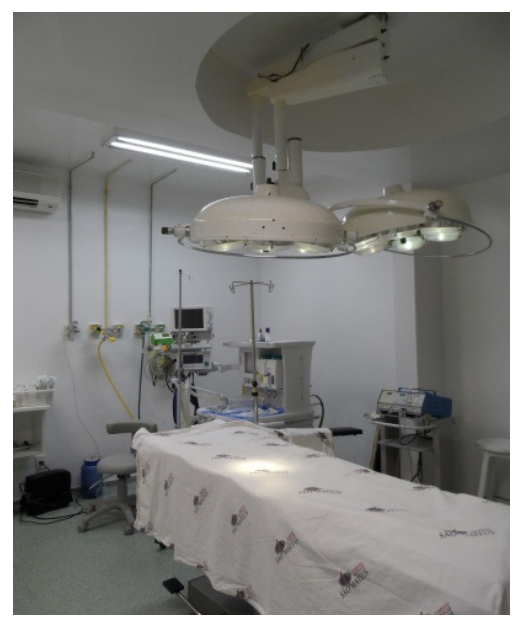

FIGURA 09 - Sala de cirurgia 5 - Hospital B FONTE: arquivo próprio

As paredes são igualmente brancas, só que a tinta tem um pouco mais de brilho devido ao fato de ser resistente à água. O piso é revestido com paviflex azul bem claro.

Assim como as demais salas de cirurgia esta possui dois sistemas distintos de iluminação fixos, o geral e o de tarefa.

O sistema de iluminação geral é composto por três luminárias sem proteção, com refletores metálicos, que acomodam 2 lâmpadas fluorescentes tubulares do tipo T8 de $40 \mathrm{~W}$ cada. Este sistema apresentou boas condições de funcionamento e limpeza nas duas visitas realizadas ao local. Na Figura 10 é possível verificar uma destas luminárias. 


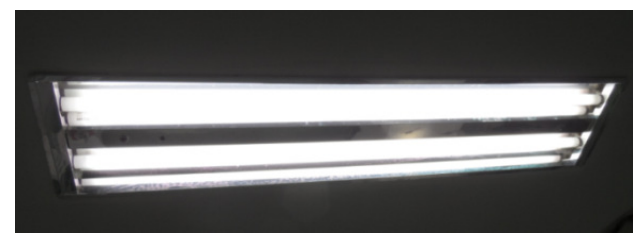

FIGURA 10 - Luminária do sistema de iluminação geral da sala de cirurgia 5 - Hospital B FONTE: arquivo próprio

O sistema de iluminação de tarefa é composto pelo foco cirúrgico. Este é composto por dois braços articuláveis com um conjunto de cinco lâmpadas de multivapores metálicos protegidas em cada braço. Estes conjuntos podem ser posicionados de acordo com a necessidade da equipe e do procedimento.

Na figura 11 é possível verificar o foco cirúrgico fechado sobre um ponto na mesa cirúrgica e a pouca influência que este exerce sobre os níveis de iluminamento próximos. Quando acionado em sua maior potência este foco atinge os 3.025,0lux.

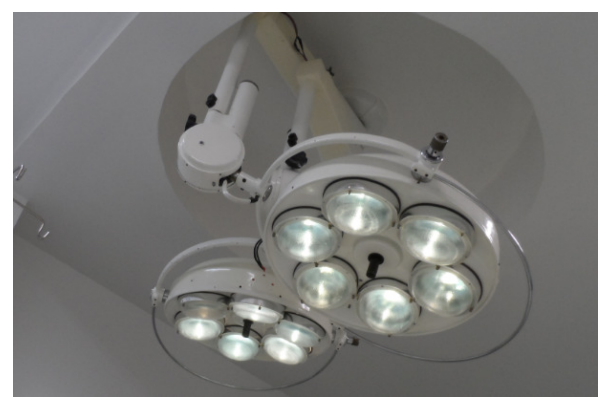

FIGURA 11 - Sistema de iluminação de tarefa da sala de cirurgia 5 - hospital B

FONTE: arquivo próprio

A média aritmética da medição realizada no dia 06/08/2012, com todo o sistema de iluminação acionado foi de 396lux. A média aritmética da medição realizada no dia 18/12/2012, após a manutenção das luminárias e com todo o sistema de iluminação acionado foi de 394lux.

\section{CONSIDERAÇÕES FINAIS}

Os dados obtidos nos dois hospitais apresentam um desacordo com a NBR 5413 (1992) na maioria dos ambientes analisados. As salas em que estes valores apresentam a maior diferença com relação ao apontado pela norma como ideal são justamente as salas em que a principal atividade do Centro Cirúrgico acontece, a sala de cirurgia.

O sistema de iluminação geral é o mais preocupante, pois os baixos níveis de iluminação atingem toda a equipe e podem comprometer o resultado do trabalho de todos os profissionais envolvidos no procedimento.

Trata-se de uma instalação comum de iluminação, a mesma que qualquer um dos profissionais atuantes dentro do Centro Cirúrgico colocaria em sua própria casa, sem preocupações com recomendações específicas para este ambiente.

Como não há sistema de iluminação complementar para a iluminação geral das salas e os trabalhadores que atuam fora do campo cirúrgico em apoio ao procedimento também não usam equipamentos auxiliares neste sentido, o fato de encontrarmos valores tão baixos é bastante preocupante, pois coloca em risco os procedimentos e a saúde dos profissioniais a longo prazo. 
Não há também preocupação com outras características do sistema, como a temperatura ideal de cor para as lâmpadas e a proteção das mesmas com aparatos de vidro ou acrílico para evitar que pequenos acidentes tornem-se problemas graves.

Os focos cirúrgicos utilzados em todas as salas de cirurgia visitadas não atingem os valores especificados em norma para a atividade que atendem, muitos deles apresentam nível de iluminamento de menos de trinta por cento do valor estipulado pela NBR 5413 (1992). Com a utilização de equipamentos auxiliares de iluminação é possível associar os fluxos e atingir os valores especificados, mas o procedimento só estaria totalmente coberto se estes equipamentos forem realmente empregados durante as cirurgias.

As salas de recuperação anestésica também apresentaram grande desconformidade com a norma. Há grandes diferenças nos níveis de iluminamento ao longo das salas e estas não contam com sistemas auxiliares de iluminação para o atendimento individual de cada paciente, o que poderia amenizar o problema.

Estas informações deixaram claro que o trabalho dos profissionais neste local, nos hospitais visitados, encontra-se prejudicado, colocando em risco a vida dos pacientes e a saúde destes trabalhadores.

É possível verificar que existe a intenção de promover uma boa iluminação nestes ambientes, pois as luminárias, apesar de não estarem em número suficiente, estão geralmente bem distribuídas e em sua maioria encontram-se em bom estado de conservação e limpeza. No entanto não houve uma preocupação no sentido de verificar se a iluminação conseguida com o sistema instalado é o suficiente para a tarefa desenvolvida no local, por desconhecimento das diferentes exigências das atividades desenvolvidas.

A tarefa de montagem de sistemas de iluminação são geralmente delegadas pelos administradores dos hospitais aos engenheiros, sem a preocupação de que estes tenham o conhecimento específico para a elaboração de projetos especiais como o de iluminação para áreas como o Centro cirúrgico.

\section{AGRADECIMENTOS}

À ELETROBRÁS e CAPES pelo apoio financeiro esta pesquisa.

\section{REFERENCIAS BIBLIOGRÁFICAS}

ASSOCIAÇÃO BRASILEIRA DE NORMAS TÉCNICAS - ABNT. NBR 5413: Iluminância de Interiores. Rio de Janeiro/ RJ, 1992. 13p.

NBR-5382 (1985) Verificação de iluminância de interiores. Rio de Janeiro/ RJ, 1985. 4p.

BOYCE, P. R. Human Factors in Lighting. 2nd ed. London and New York: Taylor \& Francis. 2003.

CADASTRO NACIONAL DE DESENVOLVIMENTO DE SAÚDE/ CNESNet. Disponível em http://cnes.datasus.gov.br/. Acesso em 02/01/2013).

DERZE, F. J. História da lluminação: Do fogo ao led. 21p. Apostila da disciplina de História da Iluminação do curso de pós graduação em Iluminação e Design de Interiores do Instituto de Pós Graduação de Goiânia - IPOG, Goiânia, 2009. 
HOSPITAL JARDIM CUIABÁ. Disponível em: http://www. hospitaljardimcuiaba.com.br/institucional.html. Acesso em 15/09/2012.

HOSPITAL SÃO MATEUS. Disponível em http://www.hmsm.com.br. Acesso em 16/09/2012.

OSRAM. Manual Luminotécnico. 2012. Disponível em: http://www.osram.com.br/osram_br/Ferramentas_\&_Catlogos/Downloads/lluminacao_Geral/Ma nual_do_Curso_lluminacao_Conceitos_e_Projetos796562/index.html. Acesso em 14/08/2012.

PEREIRA, O. R.; SOUZA, M. B. Iluminação. 120p. Apostila de conforto ambiental - iluminação do curso de pós-graduação em construção civil da universidade federal de Santa Catarina. Florianópolis, 2005.

RUAS, A. C. Conforto Térmico nos Ambientes de Trabalho. São Paulo, SP. Fundacentro, 1999. 97p.

SCHMID, A. L. A idéia de conforto: reflexões sobre o ambiente construído. Curitiba. Pacto Ambiental, 2005. 338p.

TUOTO, E. A.; Valetudinaria, Os Primeiros Hospitais. In: História da Medicina (internet). Brasil, 2010 (Disponível em Erro! A referência de hiperlink não é válida.. Acesso em 02/01/2012.

Identificação dos Autores:

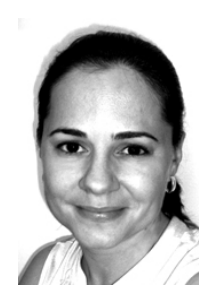

Tula Kirst Romani

Graduação em Arquitetura e Urbanismo pela Universidade de Cuiabá/ UNIC;

Mestranda pelo Programa de Pós Graduação em Engenharia de Edificações e Ambiental/ PPGEEA/ UFMT, Linha de Pesquisa: Conforto Ambiental e Eficiência Energética, E-mail: tulakirst@gmail.com

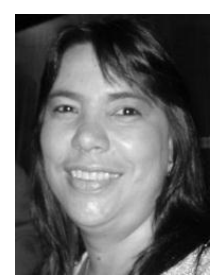

Marta Cristina de Jesus Albuquerque Nogueira

Graduação em Engenharia Civil pela Universidade Federal de Mato Grosso/ UFMT;

Professor Efetiva do Departamento de Arquitetura e Urbanismo/ UFMT;

Professora do Programa de Pós Graduação em Engenharia de Edificações e Ambiental/ PPGEEA/ UFMT, Linha de Pesquisa: Conforto Ambiental e Eficiência Energética, E-mail: mcjanp@gmail.com 